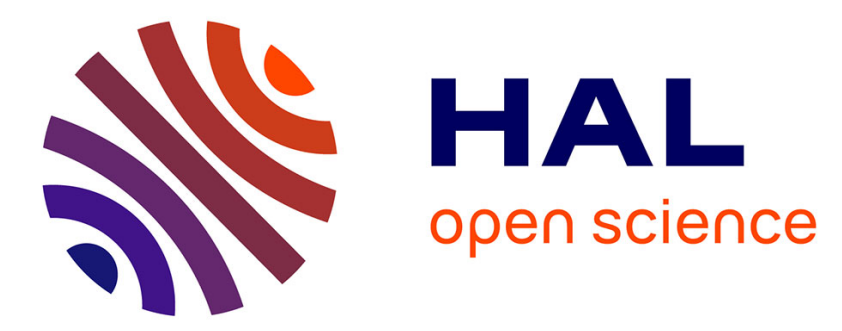

\title{
Impact of Pain Management Using the WHO Analgesic Ladder in Children with Cancer in South Egypt Cancer Institute, Assiut University
}

Salah Abdel-Hadi, Mohammed M. Ghazaly, Montaser A. Mohamed, Ahmed Mohammed Morsy

\section{To cite this version:}

Salah Abdel-Hadi, Mohammed M. Ghazaly, Montaser A. Mohamed, Ahmed Mohammed Morsy. Impact of Pain Management Using the WHO Analgesic Ladder in Children with Cancer in South Egypt Cancer Institute, Assiut University. SECI Oncology, 2014, 2014 (1), pp.2-8. 10.18056/seci2014.1. hal-01465346

\author{
HAL Id: hal-01465346 \\ https://hal.science/hal-01465346
}

Submitted on 15 Feb 2017

HAL is a multi-disciplinary open access archive for the deposit and dissemination of scientific research documents, whether they are published or not. The documents may come from teaching and research institutions in France or abroad, or from public or private research centers.
L'archive ouverte pluridisciplinaire HAL, est destinée au dépôt et à la diffusion de documents scientifiques de niveau recherche, publiés ou non, émanant des établissements d'enseignement et de recherche français ou étrangers, des laboratoires publics ou privés. 


\title{
Impact of pain management using the WHO analgesic ladder in children with cancer in South Egypt Cancer Institute, Assiut University
}

\author{
S. Abdel-Hadi ${ }^{1}$, Mohammed M. Ghazaly ${ }^{2}$, Montaser A. Mohamed ${ }^{3}$, Ahmed M. Morsy ${ }^{4}$ \\ ${ }^{1}$ Pediatric Oncology Department, National Cancer Institute, Cairo University. \\ ${ }^{2}$ Department of Pediatrics, Faculty of Medicine, Assiut University. \\ ${ }^{3}$ Anesthesiology Department, South Egypt Cancer Institute, Assiut University. \\ ${ }^{4}$ Pediatric Oncology Department, South Egypt Cancer Institute, Assiut University.
}

Correspondence should be addressed to Ahmed M. Morsy at Pediatric Oncology Department, South Egypt Cancer Institute, El-Methak St., Assiut, Egypt, Ahmedmohammed7829@yahoo.com

Received 1 January 2014; Accepted 12 January 2014

\begin{abstract}
Background: The 2012 WHO guidelines recently recommended the 2 - step strategy in managing pediatric cancer pain. There is little experimental evidence to support this practice.

Objectives: To describe characteristics \& causes of pain in department of pediatric oncology in South Egypt Cancer Institute, to ascertain the effectiveness of WHO analgesic ladder in these pediatric cancer patients \& to address side-effects occurred under treatment with opioid therapy in accordance with step $2 \& 3$ of the ladder.

Methods: During 30 months duration from (1 Jan 2011 till 30 June 2013), A prospective study was conducted on pediatric cancer patients who complained of pain \& fulfilled all the inclusion criteria for enrollment in this study. Data collected were: patients' demographics, pain characteristics \& pain intensity scores. The $1^{\text {st }} 24 \mathrm{~h}$ average intensity pain scores after change of pain therapy \& reduction of $>30 \%$ from their initial levels were used to calculate the adequacy of pain control. All patients who had persisting pain after treatment with step - 1 (paracetamol) divided into 2 groups: "group 1" received step - 2 (tramadol) \& "group 2" moved directly to step - 3 of WHO analgesic ladder (Low dose of morphine).
\end{abstract}

Results: The study included 133 pain cycles comprising a total of 1028 treatment days. Step - 1 analgesia was effective in $50.6 \%$ of all documented treatment days, while Step -2 analgesia was effective in $17.02 \%$ of all documented treatment days and Step - 3 analgesia was required in $23.6 \%$ of all documented treatment days. After failure to obtain adequate pain control on non-opioid analgesics, it was found that median average intensity pain scores in the $1^{\text {st }} 24 \mathrm{~h}$ after administration of low dose morphine as a two-step strategy (step - 3) was 1.33 , which was lower compared to those obtained after tramadol therapy (step - 2), which was 3.33 and the difference was statistically significant ( $\mathrm{p}$ value $=0.002$ ). Adverse effects which included somnolence, constipation, nausea $\& /$ or vomiting and pruritis were found to be less frequent in weak opioid drugs compared to strong opioid drugs and these differences were statistically significant ( $\mathrm{p}$ value $<0.05)$.

Conclusions: Efficacy of WHO analgesic ladder was ascertained in managing pain in children with cancer in our department. Disease-related pain was the most frequent cause of pain cycles and somatic type of pain was the most frequently occurring type. Use of low dose morphine in a two-step strategy was associated with lower pain scores, fewer drug changes for pain therapy when treatment was initiated $\&$ shorter duration of pain, but associated with more frequent side-effects than the conventional three-step WHO ladder.

Keywords: Analgesia; Cancer; Children; Oncology; Pain; WHO ladder 


\section{Introduction}

It is rather the rule than the exception that pediatric oncology patients have better survival rates than their adult counterparts. In children with cancer, the need for pain control arises mostly during curatively aimed antineoplastic treatment [1]

In Egypt, Palliative Care and cancer pain control are at an early stage of development. Very few services are available [2];[3], and there are many barriers to be faced, such as limited opioid accessibility and availability for medical use [4]; [5].

The WHO Cancer Pain Ladder, designed in 1986, is a step-by-step approach to the treatment of cancer related pain [6]; [7]; [8]; [9]. The WHO ladder states that nonopioids (Paracetamol \& NSAIDs) should be administered first, followed by weak opioids (Codeine) and then, if required, strong opioids (Morphine) [10]. While the use of non-opioids for step I and "strong" opioids for step III is widely accepted, the clinical usefulness of the "weak" opioids (or "step II" medications) in the management of cancer pain has been challenged [11].

The WHO principles of pain management [12] have recently been updated and replaced by the 2012 "WHO Guidelines on the pharmacological treatment of persisting pain in children with medical illness" [13]. The following four pharmacological principles need to be applied to achieve good analgesia with cancer: [14]

- Using a two-step strategy ("by the analgesic ladder")

- Dosing at regular intervals ("by the clock")

- Using the appropriate route of administration ("by the appropriate route")

- Adapting treatment to the individual child ("with the child")

However, as new data emerges on the safety and efficacy of tramadol or other alternative intermediate potency analgesics for the management of persisting pain in children, the two-step strategy may be revised [13].

Our aims are to describe characteristics \& causes of pain in department of pediatric oncology in South Egypt Cancer Institute, to ascertain the effectiveness of WHO analgesic ladder in these pediatric cancer patients \& to address side-effects occurred under treatment with opioid therapy in accordance with step $2 \& 3$ of the ladder.

\section{Patients and Methods \\ Sample and settings}

During 30 months duration from (1 Jan 2011 till 30 June 2013), following informed consent, a prospective study was conducted on pediatric cancer patients attending inpatient service at pediatric oncology department at South Egypt Cancer Institute(SECI)/ Assiut University, who complained of pain \& fulfilled all the inclusion criteria for enrollment in this study.

Inclusion criteria for enrollment were all new cases of pediatric cancer patients whose age from 1 year to 16 years, diagnosed with hematological malignancies or solid tumors from the time of diagnosis throughout the period of treatment $\&$ those who experienced persisting pain caused by disease, inflammation or caused by anticancer treatment.

Patients complained of procedural pain, or presented with post-operative pain, chronic complex pain or patients who were disease free survivors after finishing treatment, all were excluded from this study.

\section{Pain measurement}

For children aged 1 to 7 years, we selected the FLACC scale [15]. For children older than 7 years up to 16 years, we used the 0-10 Wong-Baker FACES pain scale (selfrated tool) [16].

\section{WONG-BAKER SCALE:}

Initial Instructions: Explain to the resident that each face is for a person who feels happy because he or she has no pain (hurt) or sad because he or she has some or a lot of pain. FACE 0 is happy because he or she doesn't hurt at all. FACE 2 hurts just a little bit. FACE 4 hurts a little more. FACE 6 hurts even more. FACE 8 hurts a whole lot. FACE 10 hurts as much as you can immagine, although you don't have to be crying to feel this bad. Ask the resident to choose the face that best describes how he or she is feeling.

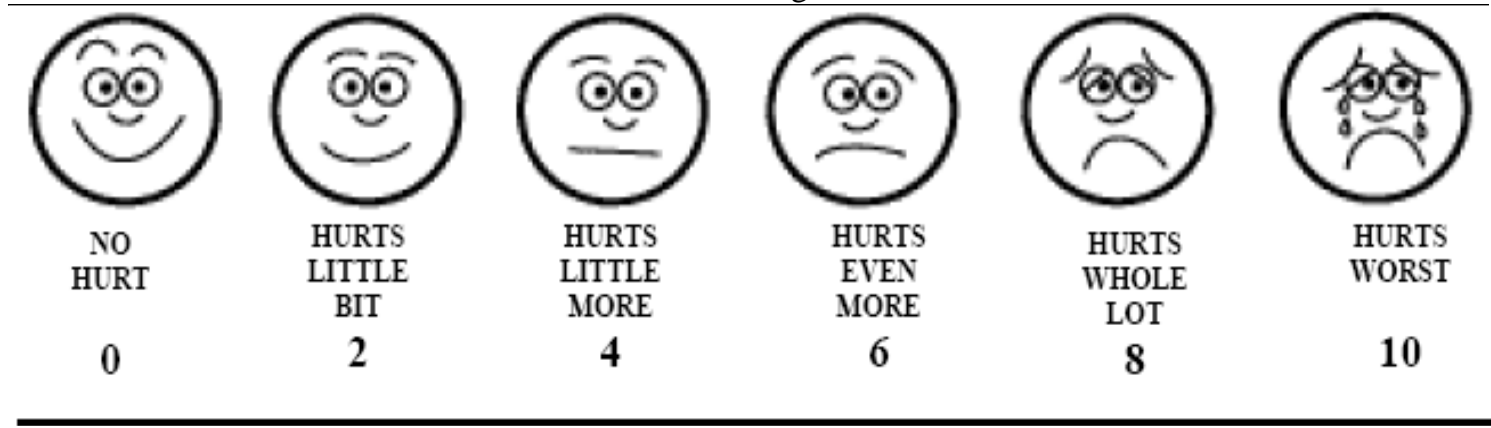

Figure (1): Wong-Baker Scale*

* Wong DL, Hockenberry-Eaton M, Wilson D, Winkelstein ML, Schwartz P. Wong's Essentials of Pediatric Nursing, 6/e, St. Louis, 2001, P. 1301. [16] 
Table (1): FLACC Scale**

\begin{tabular}{|c|c|c|c|}
\hline \multirow{2}{*}{ Category } & \multicolumn{3}{|c|}{ Scoring } \\
\hline & 0 & 1 & 2 \\
\hline Face & $\begin{array}{l}\text { No particular expression } \\
\text { on smile }\end{array}$ & $\begin{array}{l}\text { Occasional grimace or } \\
\text { frown, withdrawn, } \\
\text { disinterested }\end{array}$ & $\begin{array}{l}\text { Frequent to constant } \\
\text { quivering chin, clenched } \\
\text { jaw }\end{array}$ \\
\hline Legs & $\begin{array}{l}\text { Normal position or } \\
\text { relaxed }\end{array}$ & Uneasy, restless, tense & Kicking or legs drawn up \\
\hline Activity & $\begin{array}{l}\text { Lying quietly, normal } \\
\text { position, moves easily }\end{array}$ & $\begin{array}{l}\text { Squirming, shifting back } \\
\text { and forth, tense }\end{array}$ & Arched, rigid or jerking \\
\hline Cry & No cry (awake or asleep) & $\begin{array}{l}\text { Moans or whimpers; } \\
\text { occasional complaint }\end{array}$ & $\begin{array}{l}\text { Crying steadily, sreams } \\
\text { or sobs, frequent } \\
\text { complaints }\end{array}$ \\
\hline Consolability & Content, relaxed & $\begin{array}{l}\text { Reassured by occasional } \\
\text { tourching, hugging, or } \\
\text { being talked to; } \\
\text { distractable }\end{array}$ & Difficult to console \\
\hline
\end{tabular}

** The FLACC: A behavioral scale for scoring postoperative pain in young children, Merkel S., and others. Pediatr Nurse 23(3):293-297, 1996 [15]

\section{Data collection procedures}

The study included documented pain cycles in enrolled patients; a pain cycle was defined as a single patient's uninterrupted documentation. Each pain cycle was documented in specially designed forms; the forms contained different categories regarding the location, type, quality and cause of pain. A list stated the most frequent adverse effects of an opioid therapy and side effect severity (none, slight, strong) was included for daily checkup, daily pain scores, pain therapy used, effect of intervention on pain scores and reassessments. All data from the pain documentation forms were transferred into a spreadsheet (Excel 2007, Microsoft Corporation, USA). Data collection methods primarily relied on interviews and observations. Scoring of pain intensity was performed by our resident physicians through interview with the child.

\section{Pain treatment methods}

All patients who had persisting pain after treatment with step -1 (paracetamol) were divided into 2 groups: "group 1" received step - 2 (tramadol) \& "group 2" moved directly to step -3 of WHO analgesic ladder (Low dose of morphine).

Transdermal fentanyl patch was decided to be used as a rescue for pain cycles whose adequate pain control wasn't achieved after tramadol therapy, or as a good alternative to low dose morphine if dose limiting side effect had occurred. Fig. (2)

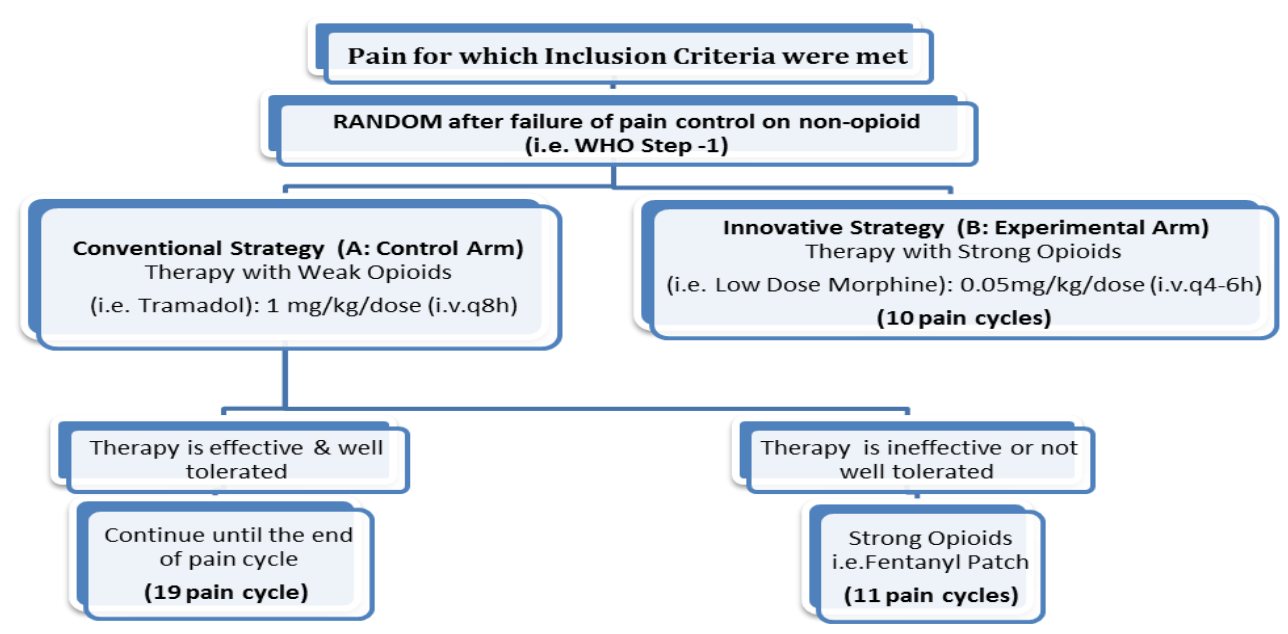

Fig. (2): The Study Design 


\section{Data analysis}

All statistical analyses were performed using SPSS (Statistical Package for Social Sciences) version 20 for Windows. Descriptive and inferential statistical method was used. For all statistical tests the threshold for statistical significance was set to $\mathrm{p}=0.05$.

\section{Results}

\section{Patients' demographics}

The present study included ninety-four patients. Their mean age was $(7.60 \pm$ SD 4.521$)$ and their median age was 6 years (range: $1-16$ years). Fifty-four patients $(57.4 \%)$ were males and 40 patients $(42.6 \%)$ were females. Of the 94 patients, $63(67 \%)$ were diagnosed as one of hematologic malignancies and 31 patients (33\%) were diagnosed as solid tumors.

During 30 months duration from (1 Jan 2011 till 30 June 2013), 133 pain cycles were documented comprising a total of 1028 treatment days (range 2-58 days). Of the 133 pain cycles, the most frequently occurring pain cycles according to patient diagnosis were NHL (33.1\%), followed by ALL (28.6\%), AML (9.8\%), Neuroblastoma (9.8\%) and Sarcomas (9.8\%).

\section{Pain characteristics}

Summary of various pain characteristics according to diagnostic group of documented pain cycles was shown in table (2).

Table (2) Various Pain Characteristics According to Diagnostic Group of Documented Pain Cycle

\begin{tabular}{|c|c|c|c|c|c|c|c|c|}
\hline \multirow{2}{*}{\multicolumn{2}{|c|}{ Pain Characteristics }} & \multicolumn{6}{|c|}{ Diagnostic Group of Pain Cycle } & \multirow{2}{*}{$\begin{array}{c}\text { Total \% } \\
\text { within all } \\
\text { diagnostic } \\
\text { groups }\end{array}$} \\
\hline & & $\begin{array}{c}A L L \\
(N=38)\end{array}$ & $\begin{array}{c}A M L \\
(N=13)\end{array}$ & $\begin{array}{c}\text { NHL } \\
(N=44)\end{array}$ & $\begin{array}{c}N B \\
(N=13)\end{array}$ & $\begin{array}{c}\text { Sarcoma } \\
(N=13)\end{array}$ & $\begin{array}{l}\text { Others } \\
(N=12)\end{array}$ & \\
\hline \multirow{2}{*}{$\begin{array}{c}\text { Pain Scale } \\
\text { Used } \\
(\mathrm{N}=133)\end{array}$} & $\begin{array}{l}\text { Age } 1-7 \\
\text { (FLACC) }\end{array}$ & $13(34.2 \%)$ & $8(61.5 \%)$ & $37(84.1 \%)$ & $12(92.3 \%)$ & $4(30.8 \%)$ & $4(33.3 \%)$ & $78(58.6 \%)$ \\
\hline & $\begin{array}{l}\text { Age > } 7-16 \\
\text { (Wong Baker } \\
\text { FACES) }\end{array}$ & $25(65.8 \%)$ & $5(38.5 \%)$ & $7(15.9 \%)$ & $1(7.7 \%)$ & $9(69.2 \%)$ & $8(66.7 \%)$ & $55(41.4 \%)$ \\
\hline \multirow{3}{*}{$\begin{array}{l}\text { Cause of Pain } \\
(N=133)\end{array}$} & Disease-related & $30(78.9 \%)$ & $9(69.2 \%)$ & $15(34.1 \%)$ & $13(100 \%)$ & $10(76.9 \%)$ & $11(91.7 \%)$ & $88(66.2 \%)$ \\
\hline & $\begin{array}{l}\text { Treatment- } \\
\text { related }\end{array}$ & $5(13.2 \%)$ & $2(15.4 \%)$ & $23(52.3 \%)$ & $0(0.0 \%)$ & $2(15.4 \%)$ & $1(8.3 \%)$ & $33(24.8 \%)$ \\
\hline & Inflammation & $3(7.9 \%)$ & $2(15.4 \%)$ & $6(13.6 \%)$ & $0(0.0 \%)$ & $1(7.7 \%)$ & $0(0.0 \%)$ & $12(9.0 \%)$ \\
\hline \multirow{3}{*}{$\begin{array}{l}\text { Type of Pain } \\
(\mathrm{N}=133)\end{array}$} & Somatic & $38(100 \%)$ & $11(84.6 \%)$ & $28(63.6 \%)$ & $10(76.9 \%)$ & $13(100 \%)$ & $3(25.0 \%)$ & \multirow{3}{*}{$\begin{array}{cc}103 & (77.4 \%) \\
22 & (16.5 \%) \\
8 & (6.0 \%)\end{array}$} \\
\hline & Visceral & $0(0.0 \%)$ & $0(0.0 \%)$ & $14(31.8 \%)$ & $1(7.7 \%)$ & $0(0.0 \%)$ & $7(58.3 \%)$ & \\
\hline & Neuropathic & $0(0.0 \%)$ & $2(15.4 \%)$ & $2(4.5 \%)$ & $2(15.4 \%)$ & $0(0.0 \%)$ & $2(16.7 \%)$ & \\
\hline \multirow{5}{*}{$\begin{array}{l}\text { Pain Location } \\
\quad(\mathrm{N}=133)\end{array}$} & Oral mucosa & $5(13.2 \%)$ & $2(15.4 \%)$ & $24(54.5 \%)$ & $0(0.0 \%)$ & $2(15.4 \%)$ & $1(8.3 \%)$ & $34(25.6 \%)$ \\
\hline & Abdominal & $0(0.0 \%)$ & $0(0.0 \%)$ & $11(25.0 \%)$ & $1(7.7 \%)$ & $0(0.0 \%)$ & $6(50.0 \%)$ & $18(13.5 \%)$ \\
\hline & $\begin{array}{l}\text { Head \& Neck } \\
\text { (not oral mucosa) }\end{array}$ & $6(15.8 \%)$ & $2(15.4 \%)$ & $2(4.5 \%)$ & $8(61.5 \%)$ & $1(7.7 \%)$ & $2(16.7 \%)$ & $21(15.8 \%)$ \\
\hline & Extremities & $22(57.9 \%)$ & $7(53.8 \%)$ & $2(4.5 \%)$ & $0(0.0 \%)$ & $9(69.2 \%)$ & $0(0.0 \%)$ & $40(30.1 \%)$ \\
\hline & Miscellaneous & $5(13.2 \%)$ & $2(15.4 \%)$ & $5(11.4 \%)$ & $4(30.8 \%)$ & $1(7.7 \%)$ & $3(25.0 \%)$ & $20(15.0 \%)$ \\
\hline
\end{tabular}

$\mathrm{N}=$ no. of pain cycles

\section{Weak opioid versus strong opioid in the $2^{\text {nd }}$ step of WHO ladder}

During use of low dose morphine, median average intensity pain scores in the $1 \mathrm{st} 24 \mathrm{~h}$ after intensification of the pain therapy was 1.33 which was lower compared to median average intensity pain scores after tramadol therapy which was 3.33 and the difference was statistically significant $(\mathrm{p}$ value $=0.002)$. The statistically significant difference between the two groups wasn't present prior to intensification of the pain therapy ( $p$ value $=0.714$ ) as was shown in Fig. (3), i.e. Patients started on low dose morphine as a strong opioid in the $2^{\text {nd }}$ step of the ladder had lower pain scores than the other group.

\section{Drug change after the $2^{\text {nd }}$ Step of WHO ladder}

Of total 30 pain cycles were on tramadol, adequate pain control wasn't achieved in 11 pain cycles (36.7\%), so fentanyl patch was administered, while of the 10 pain cycles were put on low dose morphine, adequate pain control was achieved in all cases \& side-effects were well managed by adjuvant drugs (e.g., antihistaminics, antiemetics \& prophylactic laxatives) i.e., there was no need mandated a rotation of low dose morphine to transdermal fentanyl patch. The difference between the two groups for possibility of drug change after the $2^{\text {nd }}$ step of the ladder to fentanyl transdermal patch was compared using Pearson Chi-Square test which revealed statistically significant fewer pain therapy changes after low dose morphine group than in tramadol group ( $\mathrm{p}$ value $=0.025$ ). 


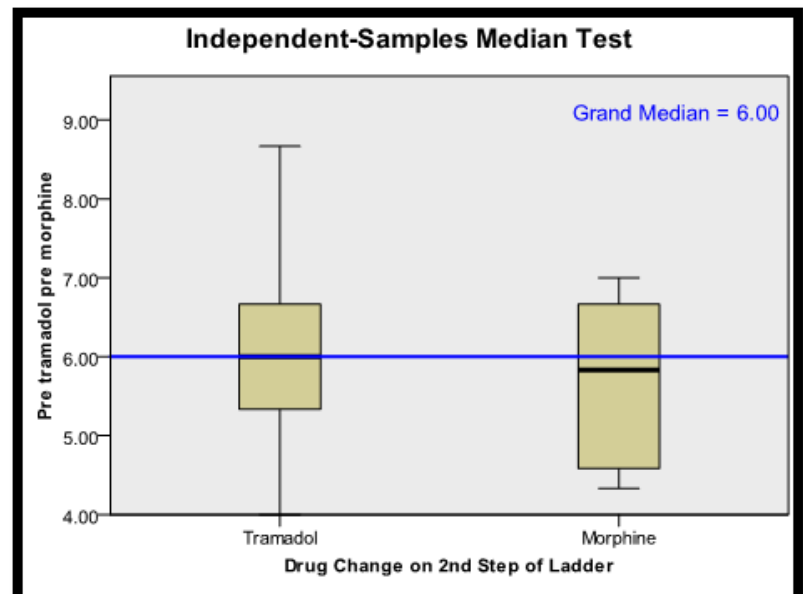

\begin{tabular}{|lr|}
\hline Total N & 40 \\
\hline Median & 6.000 \\
\hline Test Statistic & .135 \\
\hline Degrees of Freedom & 1 \\
\hline Asymptotic Sig. (2-sided test) & .714 \\
\hline
\end{tabular}

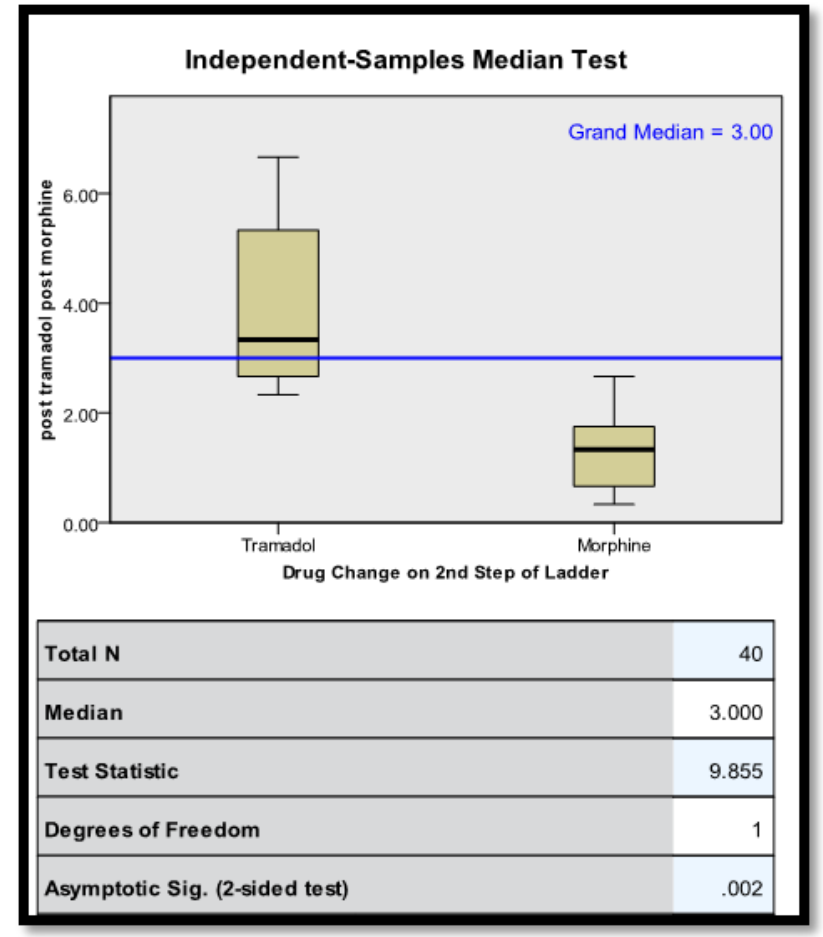

Fig. (3) The $2^{\text {nd }}$ step of WHO ladder

(Tramadol v. Morphine prior to \& post Administration)

\section{WHO ladder: '3 step' versus '2 step' strategy}

Comparison of the difference between median average pain intensity score before and after intensification of pain therapy to calculate reduction in pain intensity in the ' 3 - step strategy group' (11 pain cycles) revealed sum total reduction about $60 \%$ in two consecutive step changes of pain therapy consisted of tramadol and fentanyl patch, while reduction in the '2 step strategy group' (10 pain cycles) was about $77.6 \%$ in only one step change of pain therapy consisted of low dose morphine i.e. clinically more pain reduction \& shorter periods of pain in the low dose morphine group. Fig. (4)

\section{Adverse effects under opioid therapy according to WHO steps 2 and 3}

Adverse effects which included somnolence, constipation, nausea \&/ or vomiting and pruritis were found to be less frequent in weak opioid drugs compared to strong opioid drugs and these differences were statistically significant with ( $\mathrm{p}$ value $<0.05$ at least). Table (3)

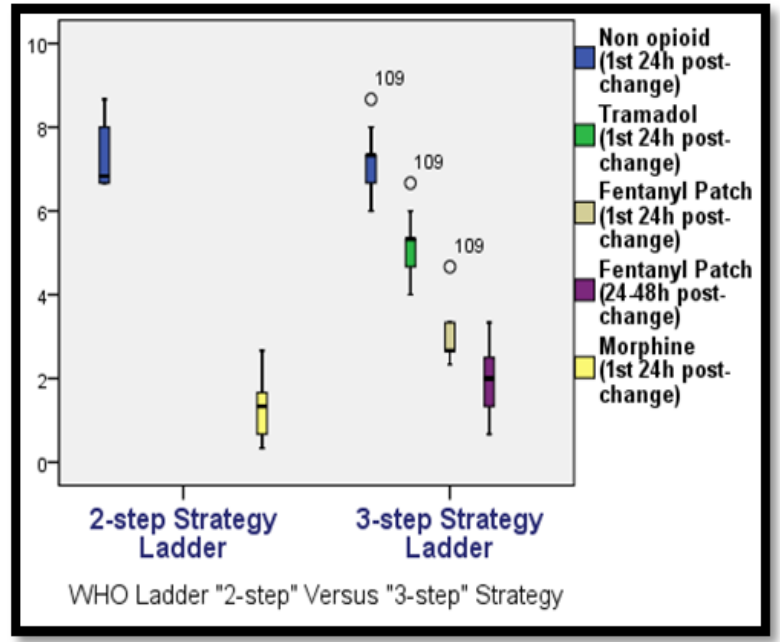

Fig. (4) Distribution of Pain Intensity Scores According to WHO Ladder Strategy 
Table (3): Summary of Adverse Effects Occurred During Treatment According to WHO Step 2 vs. Step 3

\begin{tabular}{|c|c|c|c|c|}
\hline & Somnolence & Constipation & Nausea/Vomiting & Pruritis \\
\hline \multicolumn{5}{|c|}{ Severity of adverse effects of pain therapy according to WHO step 2} \\
\hline None & $100 \%$ & $89.5 \%$ & $100 \%$ & $100 \%$ \\
\hline Slight & $0 \%$ & $5.3 \%$ & $0 \%$ & $0 \%$ \\
\hline Strong & $0 \%$ & $5.3 \%$ & $0 \%$ & $0 \%$ \\
\hline \multicolumn{5}{|c|}{ Severity of adverse effects of pain therapy according to WHO step 3} \\
\hline None & $66.7 \%$ & $57.1 \%$ & $76.2 \%$ & $76.2 \%$ \\
\hline Slight & $28.5 \%$ & $33.3 \%$ & $19 \%$ & $19 \%$ \\
\hline Strong & $4.8 \%$ & $9.6 \%$ & $4.8 \%$ & $4.8 \%$ \\
\hline $\mathrm{P}$ value & 0.006 & 0.022 & 0.023 & 0.023 \\
\hline
\end{tabular}

\section{Discussion}

The WHO step approach to pain control is used both in children and adults. However, pediatric and adult cancer pain control is different in detail [17]. Zernikow et al., 2006 [1] found in their study done on a group of pediatric cancer patients that most of them suffered from acute leukemia or a brain tumor. In contrast, three quarters of adult cancer patients experiencing pain suffer from carcinoma and their pain is mainly due to progressive tumor growth [17]. In the present study we found that $67 \%$ of the study participants was diagnosed as one of hematologic malignancies (e.g. ALL, AML or NHL), while $33 \%$ was diagnosed as one of solid tumors mainly neuroblastoma or sarcoma. Contrary to adult pain management, pain control for pediatric cancer patients is usually provided in an inpatient setting as was shown by Zernikow et al., 2006 [1] and also in the present study.

In developed countries, most cancer pain in children is related to diagnostic and therapeutic procedures and treatment. In developing countries, where large numbers of children with cancer present at an advanced stage and few have access to chemotherapy or radiotherapy, cancer pain is usually due to progression of the cancer itself [12].

Our study showed that of the 133 pain cycles, disease-related pain was the most frequent cause of pain cycles constituting $(66.2 \%)$ followed by treatmentrelated cause $(24.8 \%)$, and inflammation in $(9 \%)$. This result didn't agree with finding of German study of Zernikow et al., 2006 [1] which revealed that adverse effects of the chemotherapy were the main pain causes (in $56 \%$ ), followed by the tumor itself $(21 \%)$, an inflammation $(13 \%)$, an operation $(11 \%)$ or the radiation therapy $(4 \%)$. This difference could be attributed to that our patients presented to us with advanced stage due to delayed diagnosis, less intensive chemotherapeutic protocols were given to our patients than it should be, because of timely lack of access to necessary chemotherapeutic agents $\&$ lack of access to optimal supportive care and co-morbidities (e.g. infectious hepatitis) associated with more treatment delays in the setting of countries with limited resources constrained the ability to effect cure in children with cancer with more patients coming with relapse or resistant disease (disease-related pain). Also all cases with postoperative pain \& procedural pain were excluded from the study and most of these cases were managed by anesthesiology department in cooperation with our department.

In the present study it was found that of the 133 pain cycles, 'Somatic' pain was the most frequent type of pain cycles constituting $(77.4 \%)$ followed by 'Visceral' type $(16.5 \%)$, and 'Neuropathic' in $(6.0 \%)$. Our results were similar to results of Indian study done by Geeta et al., 2010 [18], they found that of the 39 children 37 $(95 \%)$ had nociceptive pain while, $2(5 \%)$ children had neuropathic pain. Among children with nociceptive pain, $1(3 \%)$ had visceral pain, $34(92 \%)$ had somatic pain and $2(5 \%)$ had both somatic and visceral pain. In another Indian study done by Mishra et al., 2009 [19], it was found that of 84 pediatric patients, $26(31 \%)$ patients had nociceptive pain (somatic, bony, and visceral), $12(14.3 \%)$ patients had neuropathic pain and $46(54.8 \%)$ patients had mixed pain.

In our study it was found that overall median pain cycle length was 6 days (range: 2-58 d). For pain due to treatment-related cause of pain, median pain cycle length was 8 days (range: $5-10 \mathrm{~d}$ ). For pain related to oncologic disease, median pain cycle length was 4.5 days. As in a Swedish publication [20], and in a German study done by Zernikow et al., 2006 [1], as in our study, median time requirement for pain control was less than a week. Zernikow et al. reported that overall median pain cycle length was 6 days (range: 1-27 d) and for pain due to mucositis, median pain cycle length was 7 days (range: 1-24 d). A period is far shorter than the 50-60 days which is the mean duration of pain control in non-selected adult tumor patients [17]; [21]. Our results agreed with Maltoni et al., 2005 [22] who evaluated the efficacy of an innovative two-step strategy for the treatment of chronic cancer pain to determine if it was more effective than the conventional three-step strategy. They reported that of the 54 patients in their study, the patients in the "two-step" group had better pain control and shorter periods of pain, but experienced more adverse effects, than the patients in the "three-step" group. These findings suggest that a two-step strategy is feasible for the management of cancer pain but it requires additional management of adverse effects. 
Our results also were in agreement with the study done by Marinangeli et al., 2004 [23] who prospectively compare the efficacy and tolerability of strong opioids as first-line agents with the recommendations of the WHO in terminal cancer patients. Dosages of strong opioids determined on a per case basis. Study showed that patients started on strong opioids had significantly better pain relief than patients treated according to WHO guidelines $(\mathrm{P}=0.041)$. Additionally, patients started on strong opioids required significantly fewer changes in therapy, had greater reduction in pain when a change was initiated, and reported greater satisfaction with treatment than the comparator group $(\mathrm{P}=0.041)$. Strong opioids were safe and well-tolerated, with no development of tolerance or serious adverse events. These data suggest the utility of strong opioids for firstline treatment of pain in patients with terminal cancer. Previous studies were done by Mercadante et al., 1998 [24] \& Grond et al., 1999 [25] underlined the role of opioids for moderate pain (namely, dextropropoxyphene, and tramadol respectively), in comparison with morphine, in terms of efficacy and adverse effects. In opioid-naive patients, a more favorable balance between side effects and analgesia occurred when Step 2 opioids were compared to low doses of morphine used to omit the second step. Mercadante et al., 2006 [26] reported that Initial higher doses, equivalent to about $60 \mathrm{mg}$ of oral morphine equivalents, such as those proposed in the previous studies, would have been likely to be associated with adverse effects. Even initial doses of $20 \mathrm{mg}$ /day of morphine (the minimal dose available at that time) of the study of Mercadante et al., 1998 [24] induced more adverse effects than the weak opioid drug (dextropropoxyphene) titrated for clinical use.

It is likely that a better response to morphine would have resulted from lower doses, as reported in the prospective multicenter study done by Mercadante et al., 2006 [26] to evaluate the efficacy and tolerability of very low doses of oral morphine at a starting dose of 15 $\mathrm{mg} /$ day in advanced cancer patients who no longer responsive to non-opioid analgesics. The treatment proved to be feasible, effective, and well tolerated. The result of this study was in agreement with our study result, also was similar to initial doses of morphine used in our study, where starting dose of $0.05 \mathrm{mg} / \mathrm{kg} / 4-6 \mathrm{~h}$ of intravenous low dose morphine was used (maximum starting dose of $6 \mathrm{mg} /$ day which was equivalent to 18 $\mathrm{mg}$ /day of oral morphine).

The study done by Grond et al., 1999 [25] demonstrated that high doses of oral tramadol (300-600 $\mathrm{mg} / \mathrm{d}$ ) are effective and safe in step 2 of the WHO guidelines for cancer pain relief. Analgesic efficacy and pain scores were similar to those achieved by low doses of oral morphine (The average dose of oral morphine used was $42 \pm 13 \mathrm{mg} / \mathrm{d}$ ). Tramadol was associated less frequently with constipation, neuropsychological symptoms, and pruritis; this difference was not marked, but statistically significant. This result agreed with our study in respect of safety of tramadol in step 2 of conventional ladder where tramadol dose used in our study was $1 \mathrm{mg} / \mathrm{kg} / \mathrm{dose} \mathrm{q} 8 \mathrm{~h}$ (maximum dose used was $150 \mathrm{mg} /$ day) but, in contrary to the previously described study, analgesic efficacy in our study was in favor of low dose morphine, although much lower doses of morphine used in our study (maximum starting dose of $6 \mathrm{mg} /$ day intravenous morphine which was equivalent to $18 \mathrm{mg} /$ day of oral morphine).

Finally, the present study showed that adverse effects which included somnolence, constipation, nausea \&/ or vomiting and pruritis were less frequent in weak opioid drugs compared to those of strong opioid drugs and these differences were statistically significant. These results were similar to those obtained in the study done by Zernikow et al., (2006) [1].

\section{Conclusion}

From previous results we concluded that diseaserelated pain was the most frequent cause of pain cycles and somatic type of pain was the most frequently occurring type. Patients started on low dose morphine as a strong opioid in the $2^{\text {nd }}$ step of WHO ladder 'twostep strategy' had greater reduction in pain and shorter periods of pain and required fewer changes in therapy when a change was initiated, but additional management of related side-effects than the patients in the "three-step strategy" group was needed to ensure successful implementation of the analgesic ladder..

\section{Disclosures and Acknowledgments}

Authors have no conflicts of interest to be disclosed.

\section{References}

[1] Zernikow B, Smale H, Michel E, Hasan C, Jorch $\mathrm{N}$, Andler W: Paediatric cancer pain management using the WHO analgesic ladder-results of a prospective analysis from 2265 treatment days during a quality improvement study. European Journal of Pain, 2006. 10(7): p. 587-587.

[2] Wright M, Wood J, Lynch T, Clark D: Mapping levels of palliative care development: a global view. Journal of pain and symptom management, 2008. 35(5): p. 469-485.

[3] Alsirafy, S.A., S.M. El Mesidy, and E.N. AbouElela, Where Do Egyptian Palliative Care Patients With Cancer Die? American Journal of Hospice and Palliative Medicine, 2010. 27: p. 313 315.

[4] Alsirafy, S.A., Dealing with barriers to cancer pain control in Egypt. European Journal of Palliative Care, 2010. 17: p. 10-11.

[5] Alsirafy SA, El-Mesidi SM, El-Sherief WA, Galal KM, Abou-Elela EN, Aklan NA: Opioid needs of patients with advanced cancer and the morphine dose-limiting law in Egypt. Journal of palliative medicine, 2011. 14: p. 51-54.

[6] WHO Organization, Traitement de la douleur cancéreuse. Geneva, Switzerland: World Health Organization, 1987. 
[7] Donovan, K.A., Thompson, L.M. and Jacobsen, P.B. Pain, depression, and anxiety in cancer. Handbook of Pain and Palliative Care: Biobehavioral Approaches for the Life Course, 2012: p. 615-637.

[8] Hjermstad M, Haugen D, Bennett M, Kaasa S: Pain assessment tools in palliative care and cancer. Handbook of pain and palliative care. New York: Springer, 2011.

[9] Smith, H.S., Datta, S. and Manchikanti, L. Evidence-based pharmacotherapy of chronic pain, in Handbook of Pain and Palliative Care2012, Springer. p. 471-495.

[10] Raphael J, Ahmedzai S, Hester J, Urch C, Barrie J, Williams J, Farquhar-Smith P, Fallon M, Hoskin $\mathrm{P}$, Robb K: Cancer pain: part 1: Pathophysiology; oncological, pharmacological, and psychological treatments: a perspective from the British Pain Society endorsed by the UK Association of Palliative Medicine and the Royal College of General Practitioners. Pain Medicine, 2010. 11(5): p. 742-764.

[11] Eisenberg E MF, Birkhahm J, Paladín A, Varrassi G. : Time to modify the WHO analgesic leader? Pain Clin Update, 2005. 13(5): p. 1-4.

[12] WHO Organization, Cancer pain relief and palliative care in children. 1998.

[13] WHO Organization, WHO guidelines on the pharmacological treatment of persisting pain in children with medical illnesses. Geneva: World Health Organization, 2012.

[14] Friedrichsdorf, S.J., Pain Management in Children with Cancer. 2013. available at: https://www.cure4kids.org/ums/oncopedia/case_de tail/chapter/index.php?i $=72$

[15] Merkel SI, Voepel-Lewis T, Shayevitz JR, Malviya S: The FLACC: a behavioral scale for scoring postoperative pain in young children. Pediatric nursing, 1996. 23(3): p. 293-297.

[16] Wong D, Hockenberry-Eaton M, Wilson D, Winkelstein M, Schwartz P: Wong's Essentials of Pediatric Nursing, ed. 6, St. Louis: Copyrighted by Mosby, 2001, Inc.

[17] Zech DF, Grond S, Lynch J, Hertel D, Lehmann KA: Validation of World Health Organization Guidelines for cancer pain relief: a 10-year prospective study. Pain, 1995. 63(1): p. 65-76.

[18] Geeta MG, Geetha P, Ajithkumar VT, Krishnakumar P, Suresh Kumar K, Mathews L: Management of pain in leukemic children using the WHO analgesic ladder. The Indian Journal of Pediatrics, 2010. 77(6): p. 665-668.
[19] Mishra S, Bhatnagar S, Singh M, Gupta D, Jain R, Chauhan H, Goyal G: Pediatric cancer pain management at a regional cancer center: implementation of WHO Analgesic Ladder. Middle East journal of anesthesiology, 2009. 20(2): p. 239.

[20] Flogegård, H. and G. Ljungman, Characteristics and adequacy of intravenous morphine infusions in children in a paediatric oncology setting. Medical and Pediatric Oncology, 2003. 40(4): p. 233-238.

[21] Meuser T, Pietruck C, Radbruch L, Stute P, Lehmann KA, Grond S: Symptoms during cancer pain treatment following WHOguidelines: a longitudinal follow-up study of symptom prevalence, severity and etiology. Pain, 2001. 93(3): p. 247-257.

[22] Maltoni M, Scarpi E, Modonesi C, Passardi A, Calpona S, Turriziani A, Speranza R, Tassinari D, Magnani P, Saccani D: A validation study of the WHO analgesic ladder: a two-step vs three-step strategy. Supportive Care in Cancer, 2005. 13(11): p. 888-894.

[23] Marinangeli F, Ciccozzi A, Leonardis M, Aloisio L, Mazzei A, Paladini A, Porzio G, Marchetti P, Varrassi G: Use of strong opioids in advanced cancer pain: a randomized trial. Journal of pain and symptom management, 2004. 27(5): p. 409416.

[24] Mercadante S, Salvaggio L, Dardanoni G, Agnello A, Garofalo S: Dextropropoxyphene versus morphine in opioid-naive cancer patients with pain. Journal of pain and symptom management, 1998. 15(2): p. 76-81.

[25] Grond S, Radbruch L, Meuser T, Loick G, Sabatowski R, Lehmann KA: High-Dose Tramadol in Comparison to Low-Dose Morphine for Cancer Pain Relief. Journal of pain and symptom management, 1999. 18(3): p. 174-179.

[26] Mercadante S, Porzio G, Ferrera P, Fulfaro F, Aielli F, Ficorella C, Verna L, Tirelli W, Villari P, Arcuri E: Low morphine doses in opioid-naive cancer patients with pain. Journal of pain and symptom management, 2006. 31(3): p. 242-247. 